\title{
TRPC6 regulates phenotypic switching of vascular smooth muscle cells through plasma membrane potential-dependent coupling with PTEN
}

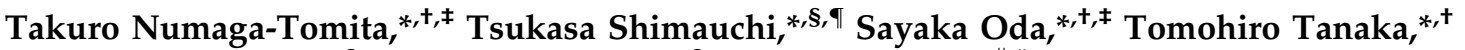 \\ Kazuhiro Nishiyama, ${ }^{\S}$ Akiyuki Nishimura, ${ }^{\S}$ Lutz Birnbaumer, ${ }^{\prime, \#}$ Yasuo Mori, ${ }^{* *}$ and Motohiro Nishida ${ }^{*,+, \pm, \$, 1}$ \\ ${ }^{*}$ National Institute for Physiological Sciences (NIPS) and ${ }^{\dagger}$ Exploratory Research Center on Life and Living Systems (ExCELLS), National \\ Institutes of Natural Sciences, Aichi, Japan; ${ }^{\ddagger}$ SOKENDAI, School of Life Science, The Graduate University for Advanced Studies, Aichi, Japan; \\ ${ }^{\S}$ Graduate School of Pharmaceutical Sciences and "Graduate School of Medical Sciences, Kyushu University, Fukuoka, Japan; "National \\ Institute of Environmental Health Sciences (NIEHS), National Institutes of Health, Research Triangle Park, North Carolina, USA; "Institute for \\ Biomedical Research (BIOMED), Catholic University of Argentina, Buenos Aires, Argentina; and ${ }^{* *}$ Department of Synthetic Chemistry and \\ Biological Chemistry, Graduate School of Engineering, Kyoto University, Kyoto, Japan
}

ABSTRACT: Vascular smooth muscle cells (VSMCs) play critical roles in the stability and tonic regulation of vascular homeostasis. VSMCs can switch back and forth between highly proliferative synthetic and fully differentiated contractile phenotypes in response to changes in the vessel environment. Although abnormal phenotypic switching of VSMCs is a hallmark of vascular disorders such as atherosclerosis and restenosis after angioplasty, how control of VSMC phenotypic switching is dysregulated in pathologic conditions remains obscure. We found that inhibition of canonical transient receptor potential 6 (TRPC6) channels facilitated contractile differentiation of VSMCs through plasma membrane hyperpolarization. TRPC6-deficient VSMCs exhibited more polarized resting membrane potentials and higher protein kinase B (Akt) activity than wild-type VSMCs in response to TGF- $\beta 1$ stimulation. Ischemic stress elicited by oxygen-glucose deprivation suppressed TGF- $\beta 1$-induced hyperpolarization and VSMC differentiation, but this effect was abolished by TRPC6 deletion. TRPC6-mediated $\mathrm{Ca}^{2+}$ influx and depolarization coordinately promoted the interaction of TRPC6 with lipid phosphatase and tensin homolog deleted from chromosome 10 (PTEN), a negative regulator of Akt activation. Given the marked up-regulation of TRPC6 observed in vascular disorders, our findings suggest that attenuation of TRPC6 channel activity in pathologic VSMCs could be a rational strategy to maintain vascular quality control by fine-tuning of VSMC phenotypic switching.Numaga-Tomita, T., Shimauchi, T., Oda, S., Tanaka, T., Nishiyama, K., Nishimura, A., Birnbaumer, L., Mori, Y., Nishida, M. TRPC6 regulates phenotypic switching of vascular smooth muscle cells through plasma membrane potential-dependent coupling with PTEN. FASEB J. 33, 9785-9796 (2019). www.fasebj.org

KEY WORDS: VSMCs $\cdot$ phenotype switching $\cdot$ membrane potential $\cdot$ transient receptor potential $\cdot \mathrm{Ca}^{+}{ }^{+}$channel

Vascular smooth muscle cells (VSMCs) play important roles in the tonus regulation of blood vessels (1). To adapt to increases and decreases of blood flow, blood vessels

ABBREVIATIONS: $\alpha$-SMA, $\alpha$-smooth muscle actin; Akt, protein kinase B; FBS, fetal bovine serum; IPAH, idiopathic pulmonary arterial hypertension; OAG, 1-oleoyl-2-acetyl-sn glycerol; OGD, oxygen-glucose deprivation; PASMC, pulmonary arterial smooth muscle cell; PDGF, platelet-derived growth factor; $\mathrm{PI}(3,4,5) \mathrm{P}_{3}$, phosphatidylinositol 3,4.5-trisphosphate; PLA, proximity ligation assay; PS, phosphatidylserine; PTEN, phosphatase and tensin homolog deleted from chromosome 10; Pyr, pyrazole; siRNA, small interfering RNA; SOCC, store-operated $\mathrm{Ca}^{2+}$ channel; TRPC6, canonical transient receptor potential 6; VSMC, vascular smooth muscle cell

${ }^{1}$ Correspondence: Division of Cardiocirculatory Signaling, National Institute for Physiological Sciences and Exploratory Research Center on Life and Living Systems, National Institutes of Natural Sciences, Higashiyama 5-1, Myodaiji-cho, Okazaki, Aichi 444-8787, Japan. E-mail: nishida@nips.ac.jp

doi: 10.1096/fj.201802811R need structural flexibility. To achieve this, VSMCs surrounding a monolayer of endothelial cells proliferate to increase the diameter of blood vessels. In addition, VSMCs are important to stabilize nascent capillaries composed of endothelial cells. To surround endothelial capillaries, precursors of VSMCs proliferate and migrate to those capillaries. Thus, VSMCs exhibit dual phenotypes: a synthetic one in which VSMCs are highly mobile and proliferative and a second contractile form in which VSMCs develop an acto-myosin contraction system and alter their own tension in response to vasoconstriction or vasodilation (1). VSMCs are capable of switching between synthetic and contractile phenotypes to maintain vessel homeostasis. However, in pathologic conditions such as atherosclerosis and pulmonary hypertension, the phenotype of VSMCs is fixed in synthetic mode, which makes blood vessels stiff and reduces their diameter $(2,3)$. As 
such, suppressing the proliferative activity of synthetic VSMCs and promoting the transition of synthetic VSMCs to a contractile phenotype could be potential therapeutic strategies for VSMC-related vessel diseases such as atherosclerosis, pulmonary hypertension, stroke, and peripheral artery disease (4). However, the molecular mechanisms underlying the transition of VSMCs from a proliferative to contractile phenotype remain obscure.

Canonical transient receptor potential 6 (TRPC6) protein forms a nonselective cation channel that is activated by diacylglycerol, which is produced by surface receptor-coupled PLC activation (5). In blood vessels, TRPC6 activation upon exposure to a vasoconstrictor, such as angiotensin II or endothelin, induces membrane depolarization and $\mathrm{Ca}^{2+}$ influx via voltage-dependent $\mathrm{Ca}^{2+}$ channels, thus resulting in eventual VSMC contraction $(6,7)$. In contrast, endothelium-stimulating vasodilators evoke release of $\mathrm{NO}$ or prostaglandin $\mathrm{I}_{2}$, which leads to activation of protein kinase G (PKG) or protein kinase A (PKA) in VSMCs, respectively (8-10). Indeed, the TRPC6 channel possesses a phosphorylation site for both PKA and PKG. Suppression of TRPC6 by phosphorylation reportedly inhibits VSMC contraction to result in vasodilation $(7,11,12)$. Although the role of TRPC6 has been well characterized in acute vessel function, its role in chronic disorders is still largely unknown. The only example is idiopathic pulmonary arterial hypertension (IPAH), for which there is a correlation between a single nucleotide polymorphism in the TRPC6 gene promoter and patients with IPAH exhibiting significantly elevated expression levels of TRPC6 mRNA and protein (13). Enhanced expression of TRPC6 caused pulmonary arterial smooth muscle cells (PASMCs) to switch from a contractile to synthetic phenotype via increased intracellular $\mathrm{Ca}^{2+}$ concentration by up-regulating store-operated $\mathrm{Ca}^{2+}$ entry (14). However, the effect elicited by suppression of TRPC6 in VSMC physiology is unknown.

In this study, primary VSMCs from mouse aorta and the mesenchymal stem cell line C3H10T1/2 were used to investigate the effect of TRPC6 deficiency on VSMC phenotypic switching. Interestingly, TRPC6 deficiency facilitated VSMC differentiation potentially via the regulation of membrane potential. Indeed, TRPC6-deficient VSMCs exhibited more hyperpolarized membrane potentials than wild-type cells. Moreover, deletion of TRPC6 increased TGF- $\beta$-induced protein kinase B (Akt) activation by suppressing the activation of lipid phosphatase, as well as phosphatase and tensin homolog deleted from chromosome 10 (PTEN). In synthetic VSMCs, TRPC6 interacted with PTEN and inhibited the production of phosphatidylinositol 3,4.5-trisphosphate $\left[\mathrm{PI}(3,4,5) \mathrm{P}_{3}\right]$, leading to attenuation of Akt signaling.

\section{MATERIALS AND METHODS}

\section{Cell culture}

Primary VSMCs were isolated from mouse aorta at $5 \mathrm{wk}$ of age as previously described (15). All protocols using mice were reviewed and approved by ethics committees at the National
Institutes of Natural Sciences or the Animal Care and Use Committee at Kyushu University, and were performed according to institutional guidelines concerning the care and handling of experimental animals. C3H10T1/2 cells were obtained from Riken BioResource Center (Tsukuba, Ibaraki, Japan). Cells were cultured in Basal Medium Eagle (BME; Thermo Fisher Scientific, Waltham, MA, USA) supplemented with $10 \%$ fetal bovine serum (FBS) and $1 \times$ penicillin/ streptomycin mixture (Nacalai, Kyoto, Japan). For induction of VSMC differentiation, cells were serum-starved for $24 \mathrm{~h}$ then stimulated with recombinant human TGF- $\beta 1$ (5 ng/ml; PeproTech, Rocky Hill, NJ, USA) in BME for the indicated times. For oxygen-glucose deprivation (OGD), cells were cultured in FBS-free DMEM without glucose (Wako, Osaka, Japan) and incubated in a multigas incubator (PHC, Tokyo, Japan) set at $1 \% \mathrm{O}_{2}$ and $5 \% \mathrm{CO}_{2}$ for $24 \mathrm{~h}$. After $24 \mathrm{~h}$ of OGD, cells were cultured in BME supplemented with either $2 \%$ FBS, 2 ng/ $\mathrm{ml}$ platelet-derived growth factor (PDGF; PeproTech), and $2 \mathrm{ng} / \mathrm{ml}$ fibroblast growth factor 2 (PeproTech), or $5 \mathrm{ng} / \mathrm{ml}$ TGF- $\beta 1$ for $24 \mathrm{~h}$ in a normal $\mathrm{CO}_{2}$ incubator. Isolation and primary culture of mouse VSMCs were as previously described (15).

\section{Small interfering RNA transfection}

C3H10T1/ 2 cells were plated $1 \mathrm{~d}$ before small interfering RNA (siRNA) transfection. siRNAs for mouse TRPC6 and negative control were purchased from Thermo Fisher Scientific (Stealth RNAi MSS212126 and siRNA Negative Control, Med GC; Waltham, MA, USA). Transfection of siRNAs was carried out using Lipofectamine RNAiMAX (Thermo Fisher Scientific) at a concentration of $20 \mathrm{nM}$ according to the manufacturer's instructions. Cells were serum-starved and stimulated with TGF- $\beta 172 \mathrm{~h}$ after siRNA transfection.

\section{Immunocytochemistry}

Cells seeded onto $12-\mathrm{mm}$ round coverslips were fixed with $4 \%$ paraformaldehyde in PBS, permeabilized with $0.5 \%$ Triton X-100 in PBS, and then stained with primary anti- $\alpha$-smooth muscle actin ( $\alpha$-SMA; MilliporeSigma, Burlington, MA, USA) or antismooth muscle $22 \alpha$ (SM22 $\alpha$ ) (Abcam, Cambridge, United Kingdom) antibodies and secondary Alexa594-conjugated anti-rabbit IgG (Thermo Fisher Scientific). Coverslips were mounted onto slide glasses with Prolong Diamond Antifade Mountant with DAPI (Thermo Fisher Scientific). Fluorescence images were acquired using a fluorescence microscope with $\times 100$ objective (BX-Z710; Keyence, Osaka, Japan). Combinations of either a 565-nm excitation filter and 535-675-nm band-pass filter for emission or a 400-nm excitation filter and 410-510-nm band-pass filter for emission were utilized for imaging of Alexa594 or DAPI, respectively. Mean fluorescence intensity/ pixel of each cell (at least 30 cells/image) was analyzed with ImageJ software (National Institutes of Health, Bethesda, MD, USA).

\section{Measurement of membrane potential}

Cells were loaded with $2 \mu \mathrm{M} \mathrm{DiBAC} 4$ (3) (Thermo Fisher Scientific) containing HEPES-buffered saline solution [HBSS; $140 \mathrm{mM} \mathrm{NaCl}, 5.6 \mathrm{mM} \mathrm{KCl}, 1.8 \mathrm{mM} \mathrm{CaCl}, 1 \mathrm{mM} \mathrm{MgCl}_{2}$, $10 \mathrm{mM}$ glucose, and $10 \mathrm{mM}$ HEPES (pH 7.4 adjusted with $\mathrm{NaOH})]$ at $37^{\circ} \mathrm{C}$ for $30 \mathrm{~min}$. Fluorescence of $\mathrm{DiBAC}_{4}$ (3) was measured at an excitation wavelength of $488 \mathrm{~nm}$ with a fluorescence microscope with $\times 20$ objectives (BX-Z710). Mean fluorescence intensity/pixel of each cell (at least 100 cells/ image) was analyzed with ImageJ software. 


\section{Western blotting}

For membrane fractionation, cells were lysed by sonication (Waken Btech, Kyoto, Japan) in hypotonic lysis buffer containing 20 mM Tris-HCl (pH 7.4), 10 mM EDTA, 5 mM EGTA, and proteinase inhibitor cocktail (Nacalai). Membrane fractions were precipitated by ultracentrifugation at $40,000 \mathrm{~g}$ at $4^{\circ} \mathrm{C}$ for $60 \mathrm{~min}$. The precipitate was dissolved in hypotonic lysis buffer supplemented with $0.1 \%$ SDS, $0.5 \%$ sodium deoxycholate, and $1 \%$ NP- 40 . For western blot of Akt and SM22 $\alpha$, cells were lysed in 1\% Triton X-100 lysis buffer containing $20 \mathrm{mM}$ Tris- $\mathrm{HCl}$ (pH7.8), $140 \mathrm{mM} \mathrm{NaCl}, 1 \%$ Triton X-100, 2 mM EDTA, 10\% glycerol, and Halt's phosphatase and protease inhibitor cocktail (Thermo Fisher Scientific). For western blotting, samples were fractionated by SDS-PAGE and then transferred onto PVDF membranes (Merck, Darmstadt, Germany). Proteins of interest were detected with the indicated antibodies. After incubation with secondary antibody, bands were visualized with Western Lightning Plus ECL (PerkinElmer, Waltham, MA, USA). Images were captured with an ImageQuant LAS 4000 and quantified using ImageQuant TCL software (GE Healthcare Life Science, Chicago, IL, USA). Anti-TRPC6 (Alomone labs, Jerusalem, Israel), anti-glyceraldehyde 3-phosphate dehydrogenase (Santa Cruz Biotechnology, Dallas, TX, USA), antiSM22 $\alpha$, anti-phospho-Akt (Ser473), anti-Akt, and anti-PTEN (Cell Signaling Technology, Danvers, MA, USA) antibodies were used at 1:2000 dilutions.

\section{Electrophysiology}

1-Oleoyl-2-acetyl-sn glycerol (OAG)-induced currents were measured using the whole-cell patch-clamp technique with an EPC-10 patch-clamp amplifier (HEKA Elektronik, Lambrecht/ Pfalz, Germany). Patch electrodes with a resistance of 3-4 M $\Omega$ (when filled with internal solution) were made from 1.5-mm borosilicate glass capillaries (Sutter Instrument, Novato, CA, USA). Voltage-clamp experiments were performed at a holding potential of $-40 \mathrm{mV}$, with recordings sampled at $2.0 \mathrm{kHz}$ and filtered at $2.9 \mathrm{kHz}$. To analyze $I-V$ relationships, ramp pulses from -100 to $100 \mathrm{mV}$ over $250 \mathrm{~ms}$ were applied every $30 \mathrm{~s}$. Cells were allowed to settle in the perfusion chamber in external solution containing $140 \mathrm{mMNaCl}, 5.6 \mathrm{mM} \mathrm{KCl}, 1 \mathrm{mMMgCl}_{2}, 2 \mathrm{mM}$ $\mathrm{CaCl}_{2}, 10 \mathrm{mM}$ HEPES, and $10 \mathrm{mM}$ glucose ( $\mathrm{pH}$ 7.4). The pipette solution contained $120 \mathrm{mM} \mathrm{CsOH}, 120 \mathrm{mM}$ aspartate, $20 \mathrm{mM}$ $\mathrm{CsCl}, 2 \mathrm{mM} \mathrm{MgCl}, 5 \mathrm{mM}$ EGTA, $1.5 \mathrm{mM} \mathrm{CaCl}_{2}, 10 \mathrm{mM}$ HEPES, $2 \mathrm{mM}$ ATP-Na $2,0.1 \mathrm{mM}$ GTP, and $10 \mathrm{mM}$ glucose (pH 7.2, adjusted with Tris base). Cells were superfused with standard external solution in the presence or absence of OAG applied focally using a Y-tube perfusion system. Cells were stimulated with TGF- $\beta 1$ for $24 \mathrm{~h}$ and recorded $3 \mathrm{~h}$ after plating on glass coverslips. Pyrazole (Pyr, $10 \mu \mathrm{M}) 2$ was focally applied to cells beginning 3 min before OAG stimulation.

\section{Boyden chamber cell migration assay}

Cell migration was measured with a Boyden chamber assay. Mouse VSMCs were serum-starved overnight and seeded into the upper chamber of Transwell culture inserts (8-mm prepolycarbonate membrane; Corning, Corning, NY, USA). PDGF-BB (50 ng/ml, human recombinant; R\&D Systems, Minneapolis, MN, USA) was added to the bottom chambers. Six hours after PDGF treatment, nonmigrating cells on the upper surface of the filter were removed, and migrated cells on the lower surface of the filter were permeabilized and stained with hematoxylin (MilliporeSigma). Cells were observed by inverted microscopy with $\times 10$ objective lens and counted. Four fields/ Transwell insert were analyzed. Averaged data from 3 independent experiments were calculated.

\section{Cell proliferation assay}

Mouse VSMCs were seeded into 12 -well plates $\left(1 \times 10^{4}\right.$ cells/ well). After serum starvation overnight, cells were treated with 50 $\mathrm{ng} / \mathrm{ml}$ PDGF-BB. Cells were trypsinized and counted with a hemocytometer every $24 \mathrm{~h}$ until $7 \mathrm{~d}$ after treatment.

\section{Duolink proximity ligation assay}

Mouse VSMCs were fixed with 3\% v/v glyoxal (MilliporeSigma) solution for $30 \mathrm{~min}$ on ice and another $30 \mathrm{~min}$ at room temperature. Glyoxal was quenched with $100 \mathrm{mM} \mathrm{NH}_{4} \mathrm{Cl}$ for $20 \mathrm{~min}$ at room temperature. Cells were permeabilized with Tris-buffered saline solution ( $\mathrm{pH} 7.4$ ) containing $0.5 \%$ Triton X-100 for $10 \mathrm{~min}$ and then blocked with Tris-buffered saline solution containing $0.1 \%$ Triton $\mathrm{X}-100$ and $1 \%$ bovine serum albumin for $1 \mathrm{~h}$ at room temperature. Cells were incubated with anti-TRPC6 antibody and anti-PTEN antibody (A2B1; Santa Cruz Biotechnology) at $4^{\circ} \mathrm{C}$ overnight. Incubation with proximity ligation assay (PLA) probes and detection were carried out according to the manufacturer's instructions (Duolink In Situ Red Starter Kit Mouse/ Rabbit; MilliporeSigma). Images were acquired by confocal laser microscopy with a $\times 60$ objective lens (Nikon, Tokyo, Japan). The number of PLA signals in single cells was analyzed with ImageJ software.

\section{Measurement of changes in $\left[\mathrm{Ca}^{2+}\right]_{i}$}

Measurement of changes in $\left[\mathrm{Ca}^{2+}\right]_{\mathrm{i}}$ was carried out as previously described (16). Briefly, cells were loaded with the fluorescent $\mathrm{Ca}^{2+}$ indicator Fura-2 (Dojindo, Kumamoto, Japan) and fluorescence images recorded from cells incubated in HBSS were analyzed with a video image analysis system (Aqua Cosmos; Hamamatsu Photonics, Hamamatsu, Japan). Hyperforin was purchased from MilliporeSigma.

\section{Statistics}

Results are presented as means \pm SEM of 3 or 5 independent experiments using primary mouse VSMCs or C3H10T1/2 cells, respectively. Statistical significance was determined using an unpaired $t$ test for 2-group comparisons, or 2-way ANOVA with Sidak's post hoc test for comparison of 3 or more groups. Significance was considered at a value of $P<0.05$.

\section{RESULTS}

\section{Suppression of TRPC6 promoted VSMC differentiation}

We first analyzed the involvement of TRPC6 in VSMC phenotypic switching using primary murine VSMCs isolated from either wild type $[\mathrm{TRPC} 6(+/+)]$ or TRPC6 knockout [TRPC6 $(-/-)$ ] mice. TRPC6 $(-/-)$ cells exhibited increased $\alpha$-SMA immunofluorescence compared with TRPC6(+/+) cells in response to serum withdrawal (Fig. 1A), indicating differentiation of VSMCs was facilitated in TRPC6 $(-/-)$ cells. We next analyzed properties of migration and proliferation of VSMCs to analyze the effect of TRPC6 deficiency on the synthetic phenotype of VSMCs. PDGF is the major cytokine for mural cell recruitment to capillaries (17). Upon PDGF stimulation, 
A
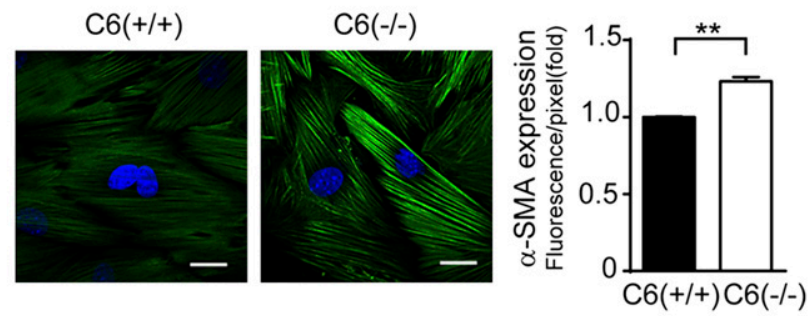

B

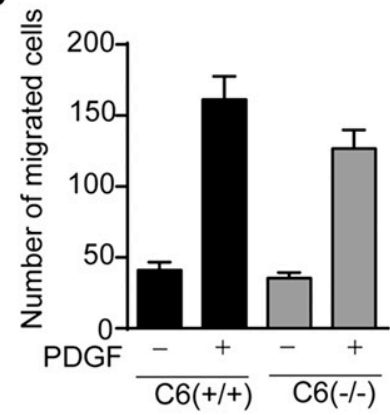

C

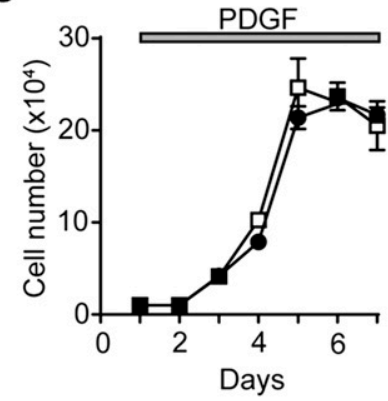

D

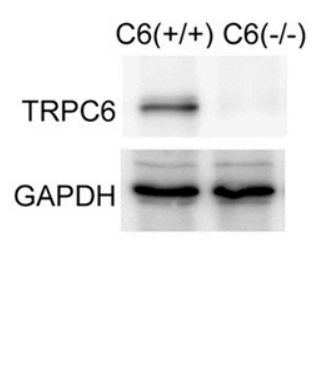

$\mathbf{E}$

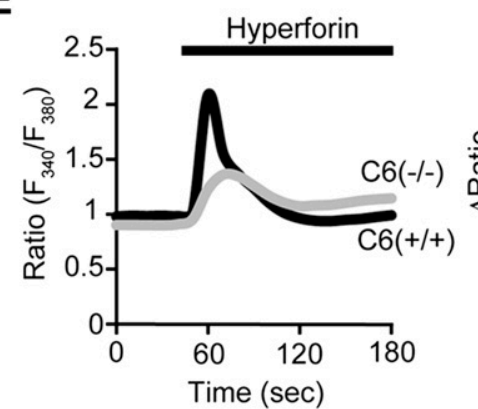

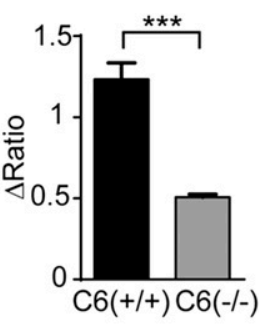

Figure 1. TRPC6 deletion facilitated VSMC differentiation but not proliferation. A) Representative immunostaining images of $\alpha$-SMA in VSMCs $3 \mathrm{~d}$ after serum withdrawal. Scale bars, $20 \mu \mathrm{m}$. Nuclei were visualized with DAPI. Quantification of $\alpha$-SMA fluorescence intensity (right, $n=3) . B, C)$ Quantification of PDGF-induced cell migration $(B, n=3)$ and proliferation $(C, n=3)$ of C6 $(+/+)$ (closed circle) and C6 $(-/-)$ (open square) VSMCs. Cells were stimulated with PDGF (2 $\mathrm{ng} / \mathrm{ml}) \mathrm{for} 12 \mathrm{~h}$ in Boyden chamber assays. D) Expression of TRPC6 protein in mouse aortic VSMCs. Representative blots from 3 independent experiments are shown. GAPDH, glyceraldehyde 3-phosphate dehydrogenase. E) Hyperforin-induced $\mathrm{Ca}^{2+}$ responses in C6(+/+) and C6( $(-/-)$ VSMCs. Cells were stimulated with hyperforin $(10 \mu \mathrm{M})$. Averaged peak $\mathrm{Ca}^{2+}$ increases are shown $[$ right, $n=40$ for C6 $(+/+), n=42$, $n=54$ for $\mathrm{C} 6(-/-)]$. Data represent means \pm SEM. $* * P<0.01, * * * P<0.001$.

neither cell migration nor proliferation were affected by TRPC6 deletion (Fig. 1B, C). Loss of TRPC6 protein expression was confirmed by western blot analysis (Fig. 1D). Hyperforin, a TRPC6 channel activator (18), increased intracellular $\mathrm{Ca}^{2+}$ concentration $\left(\left[\mathrm{Ca}^{2+}\right]_{\mathrm{i}}\right)$ in TRPC6(+/+) VSMCs, but this effect was significantly reduced in TRPC6 (-/-) VSMCs (Fig. 1E). The remaining $\left[\mathrm{Ca}^{2+}\right]_{\mathrm{i}}$ increase in TRPC6(-/-) cells might be caused by the release of $\mathrm{Ca}^{2+}$ from intracellular organelles such as mitochondria (19). These data suggest that TRPC6 deficiency does not promote or compromise the proliferative or migratory activities of synthetic VSMCs.

\section{TRPC6 deficiency polarized membrane potential}

It has been recognized that more quiescent and fully differentiated cells exhibit relatively polarized membrane potentials ranging from -50 to $-90 \mathrm{mV}$, whereas more plastic stem cells exhibit less polarized membrane potentials averaging between -10 and $-40 \mathrm{mV}$ (20). TRPC6 is reportedly involved in the regulation of membrane potential in VSMCs and bone marrow stromal cells $(21,22)$. Therefore, we next assessed the membrane potential in synthetic and contractile VSMCs in the presence or absence of TRPC6 gene expression. Cells loaded with the slow kinetic membrane potential dye $\mathrm{DiBAC}_{4}$ (3) were evaluated for florescence intensity (23). TGF- $\beta 1$ treatment significantly reduced $\mathrm{DiBAC}_{4}$ (3) fluorescence in VSMCs, suggesting that the induction of switching to a contractile phenotype elicited by exposure to TGF- $\beta 1$ caused hyperpolarization of resting membrane potential compared with synthetic cells (Fig. 2A). In contrast, deletion of TRPC6 hardly affected resting membrane potential in synthetic VSMCs. Moreover, contractile TRPC6 $(-/-)$ cells exhibited more hyperpolarized membrane potentials than contractile TRPC6 $(+/+)$ cells (Fig. $2 A$ ). Simultaneously, TGF- $\beta 1$ stimulation increased SM22 $\alpha$ expression to a higher level in TRPC6 $(-/-)$ cells compared with TRPC6 $(+/+)$ cells (Fig. 2B). These data suggest that TRPC6 functions to maintain resting membrane potential at a relatively depolarized state and, moreover, there is a correlation between membrane potential and VSMC phenotypic switching in which TRPC6 plays a key role.

\section{TRPC6 negatively regulated switching to a contractile phenotype by suppressing Akt activation}

We next investigated whether VSMC differentiation affected TRPC6 channel activity. As a VSMC differentiation model, we used the C3H10T1/2 mesenchymal stem cell line, a well-defined VSMC differentiation model. Stimulation with TGF- $\beta$ has been shown to differentiate $\mathrm{C} 3 \mathrm{H} 10 \mathrm{~T} 1 / 2$ cells into smooth muscle cells (24-26). To reveal the relationship between VSMC 


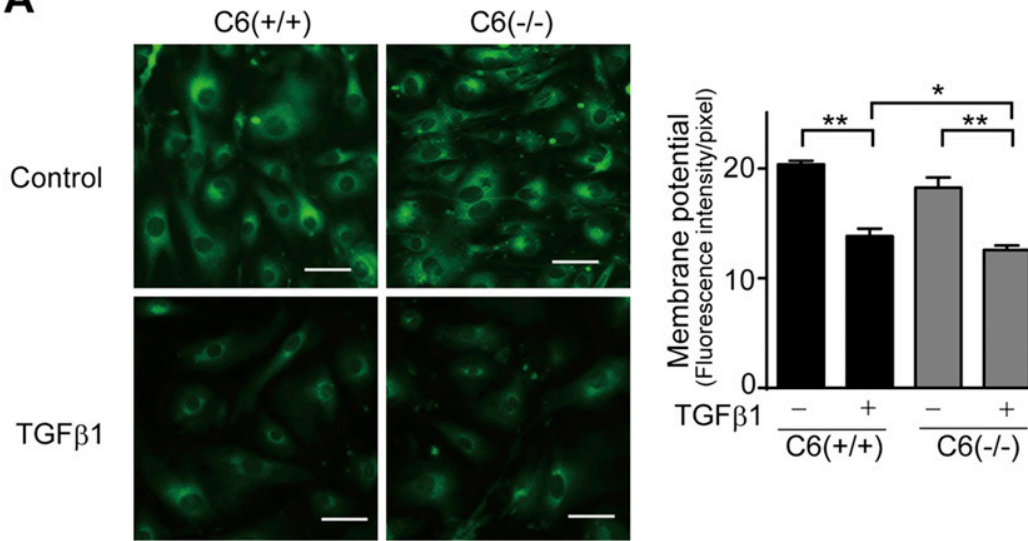

Figure 2. TRPC6 deletion hyperpolarized resting membrane potential in VSMCs. A) Representative images of $\mathrm{DiBAC}_{4}(3)$ fluorescence in in $\mathrm{C} 6(+/+)$ and $\mathrm{C} 6(-/-)$ VSMCs treated with TGF- $\beta 1$. Cells were treated with TGF- $\beta 1$ ( $5 \mathrm{ng} /$ $\mathrm{ml})$ for $48 \mathrm{~h}$ after 24-h serum starvation. Control cells were cultured in the presence of $20 \%$ FBS. Scale bars, $50 \mu \mathrm{m}$. Averaged fluorescence intensity/pixel was quantitated (right, $n=4)$. B) Representative immunostaining images of SM22 $\alpha$ in VSMCs stimulated with TGF- $\beta 1(5 \mathrm{ng} / \mathrm{ml})$ for $48 \mathrm{~h}$. Scale bars, $50 \mu \mathrm{m}$. Nuclei were visualized with DAPI. Average fluorescence intensities/pixel were quantitated (right, $n=3$ ). Data represent means \pm sEM.

$* P<0.05, * * P<0.01$.
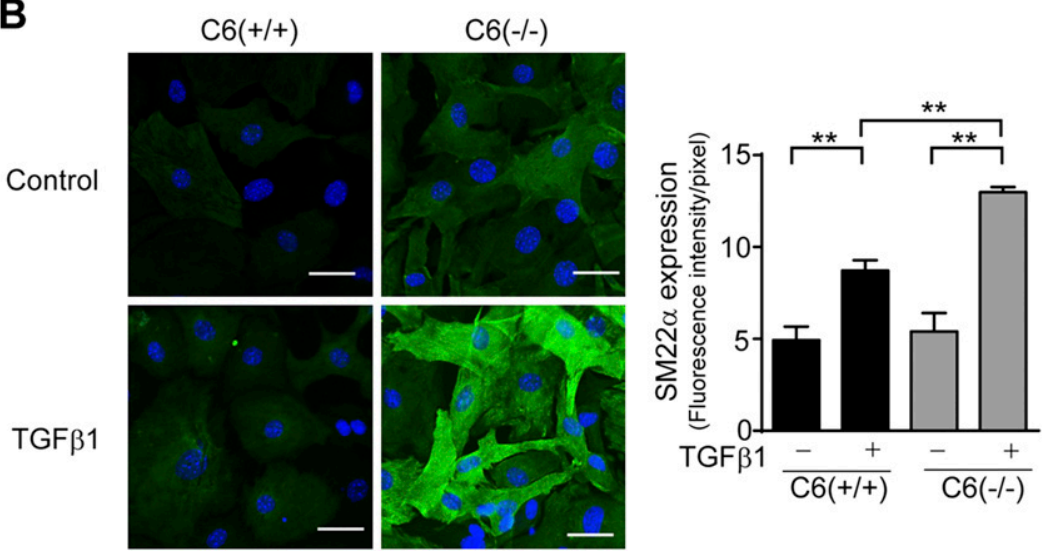

differentiation and TRPC6 activity, we analyzed the effect of TGF- $\beta 1$ on TRPC6 channel activity in C3H10T1/2 cells using whole-cell patch-clamp methodology. Endogenous TRPC6 channel-dependent current was induced by stimulating C3H10T1/2 cells with OAG, a membrane permeable analog of 1,2-diacylglycerol (Fig. 3A, B). OAG-induced current was significantly suppressed by treatment with Pyr2 (also known as BTP2), a broad inhibitor of TRPC channels (16). TGF$\beta 1$-treated cells exhibited a marked reduction of OAG-induced current, suggesting that VSMC-like differentiated cells have less TRPC6 activity than proliferative cells (Fig. $3 A, B$ ). In addition, treatment with TGF- $\beta 1$ hardly reduced TRPC6 mRNA levels (Fig. $3 C)$, suggesting that TGF- $\beta 1$ induces differentiation of C3H10T1/2 cells concomitant with suppression of TRPC6 channel activity but without TRPC6 downregulation. siRNA transfection significantly suppressed TRPC6 expression at both mRNA and protein levels (Fig. $3 C, D)$. Next, we investigated how TRPC6 knockdown affected VSMC differentiation of C3H10T1/2 cells. Stimulation with TGF- $\beta 1$ increased the protein abundances of differentiation markers $\alpha$-SMA and SM $22 \alpha$, indicated by both immunofluorescence and western blot analyses (Fig. $3 E, H)$. siRNA-knockdown of TRPC6 had no impact on basal levels of $\alpha$-SMA or SM22 $\alpha$ proteins, although it markedly increased TGF- $\beta 1$-stimulated inductions of those markers (Fig. 3E, H). In contrast, overexpression of TRPC6 almost completely suppressed $\alpha$-SMA induction in TGF- $\beta 1$-stimulated C3H10T1/2 cells (Fig. 3F). These data suggest that TRPC6 negatively regulates the induction of VSMC differentiation. Differentiation of C3H10T1/2 cells into VSMCs is reportedly regulated by Akt (27). We found that knockdown of TRPC6 significantly increased TGF- $\beta 1$-induced Akt phosphorylation at Ser473 (Fig. 3G). To confirm the involvement of Akt activation in facilitating VSMC differentiation through TRPC6 down-regulation, cells were treated with LY-294002, a PI3K inhibitor. LY-294002 suppressed the increase of SM22 $\alpha$ protein induced by TGF- $\beta 1$ at the same level in both control and TRPC6-knockdown cells (Fig. 3H). These data suggest that TRPC6 activity is inversely correlated with VSMC differentiation via regulation of the Akt signaling pathway.

\section{Ischemic conditions suppressed VSMC differentiation in a TRPC6-dependent manner}

We next examined whether ischemic conditions impacted TGF- $\beta 1$-induced differentiation of C3H10T1/2 cells, as ischemic-reperfusion causes an aberrant increase of reactive oxygen species-the most important driver of vessel disease (28). Exposure to OGD significantly suppressed TGF- $\beta 1$-induced increases of SM22 $\alpha$ expression in siControl-transfected C3H10T1/2 cells (Fig. 4A). However, strikingly, knockdown of TRPC6 increased SM22 $\alpha$ expression even in OGD-treated cells (Fig. 4A). TRPC6(-/-) primary VSMCs exhibited 
A

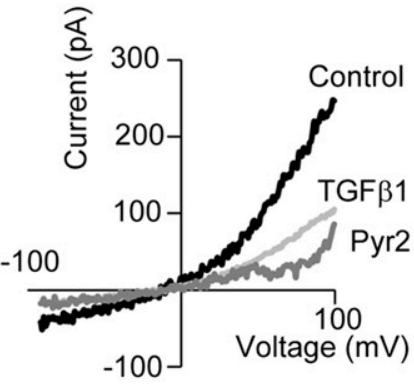

E
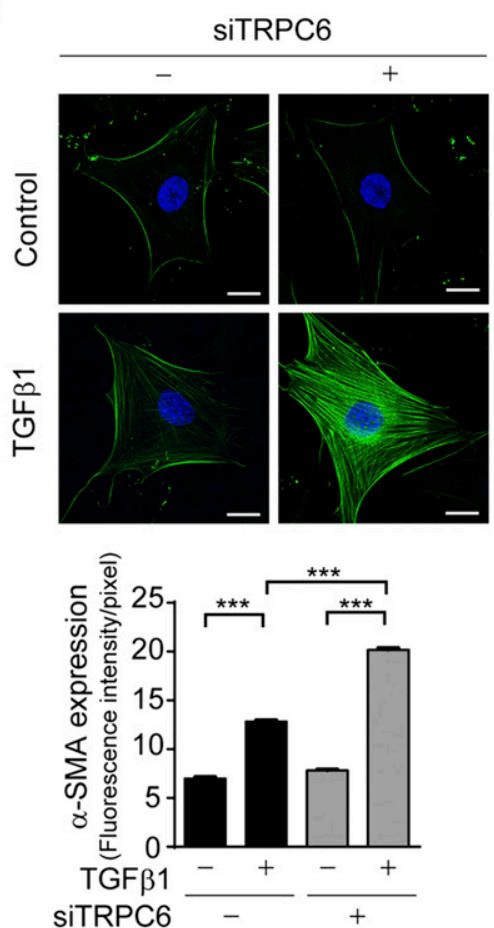

H

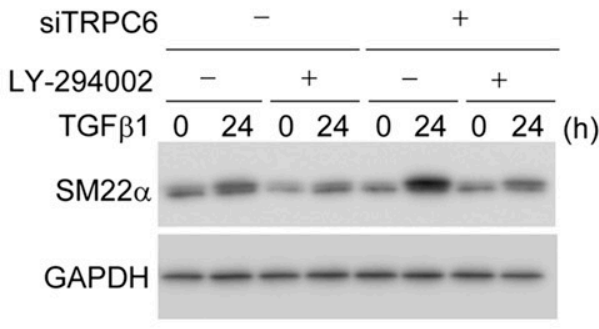

B

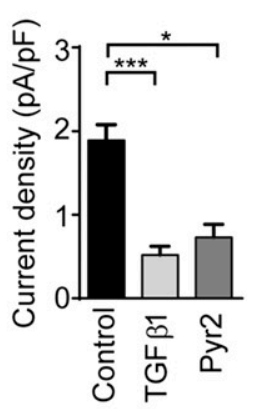

F

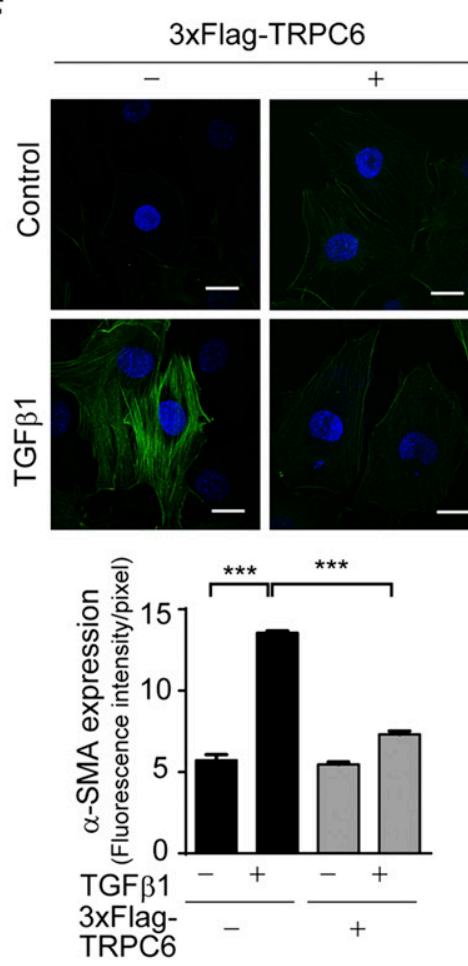

C

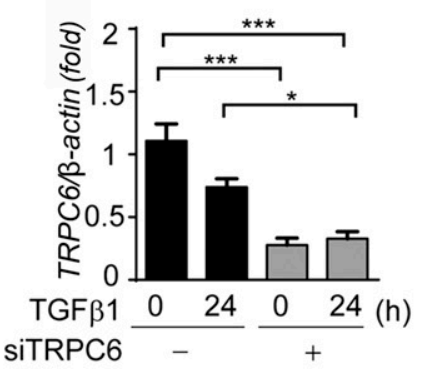

D

SiTRPC6 - +

TRPC6

GAPDH - -

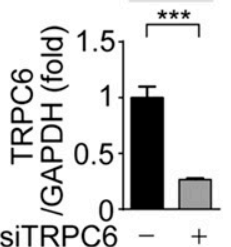

G
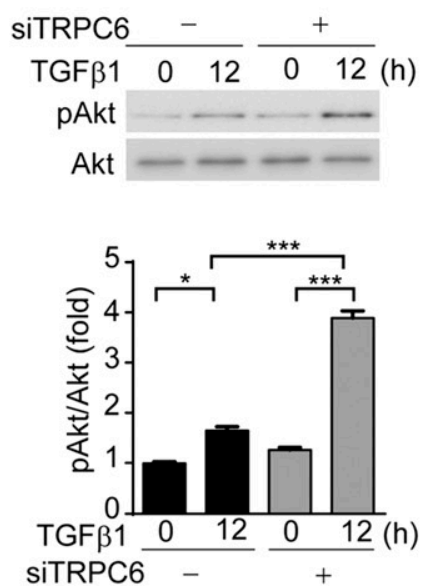

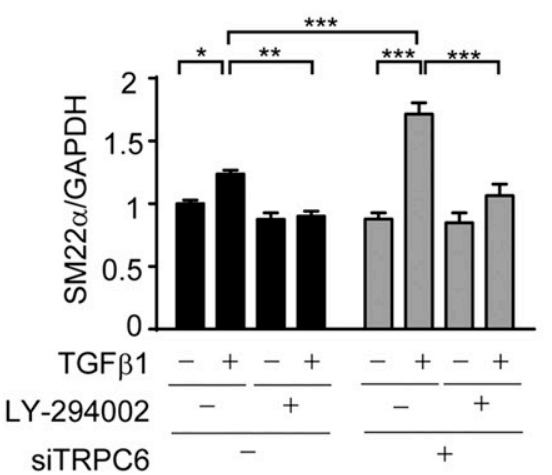

Figure 3. TRPC6 deletion facilitated VSMC differentiation by up-regulating the Akt signaling pathway in C3H10T1/2 cells. $A, B$ ) OAG-induced cation current in C3H10T1/2 cells. $I-V$ relationship $(A)$ and averaged maximum current density $(B) 2$ min after OAG $(10 \mu \mathrm{M})$ stimulation ( $n=6$ for control cells, $n=5$ for TGF- $\beta 1$-treated cells, $n=5$ for Pyr2-treated cells). Cells were treated with TGF- $\beta 1(5 \mathrm{ng} / \mathrm{ml})$ for $48 \mathrm{~h}$ and plated on coverslips. Pyr2 $(10 \mu \mathrm{M})$ was applied focally 3 min before OAG stimulation and throughout the recording. $C$ ) mRNA expression of TRPC6 in siTRPC6-transfected C3H10T1/2 cells $(n=5)$. Cells were treated with TGF- $\beta 1$ for 24 h. $D$ ) Expression of TRPC6 protein in siRNA-transfected C3H10T1/2 cells normalized to glyceraldehyde 3phosphate dehydrogenase (GAPDH) protein $(n=5)$. E) Immunofluorescence of $\alpha$-SMA in TGF- $\beta 1$-stimulated C3H10T1/2 cells $(n=5)$. Scale bars, $20 \mu \mathrm{m}$. Nuclei were visualized with DAPI. $F)$ Immunofluorescence of $\alpha$-SMA in C3H10T1/2 cells stably expressing $3 \times$ Flag-tagged TRPC6 $(n=5)$. Scale bars, $20 \mu \mathrm{m}$. Nuclei were visualized with DAPI. $G)$ Akt phosphorylation in TGF$\beta 1$-stimulated C3H10T1/2 cells transfected with siTRPC6. pAkt, phosphorylated Akt. Data were normalized to untreated siControl-transfected cells $(n=5) . H)$ SM22 $\alpha$ expression in TGF- $\beta 1$-stimulated C3H10T1/2 cells treated with LY-294002 (50 $\mu$ M). Cells were pretreated with LY-294002 for 30 min before TGF- $\beta 1$ treatment $(24 \mathrm{~h})$. Data were normalized to untreated siControltransfected cells $(n=5)$. Data represent means \pm SEM. $* P<0.05, * * P<0.01, * * * P<0.001$. 
A
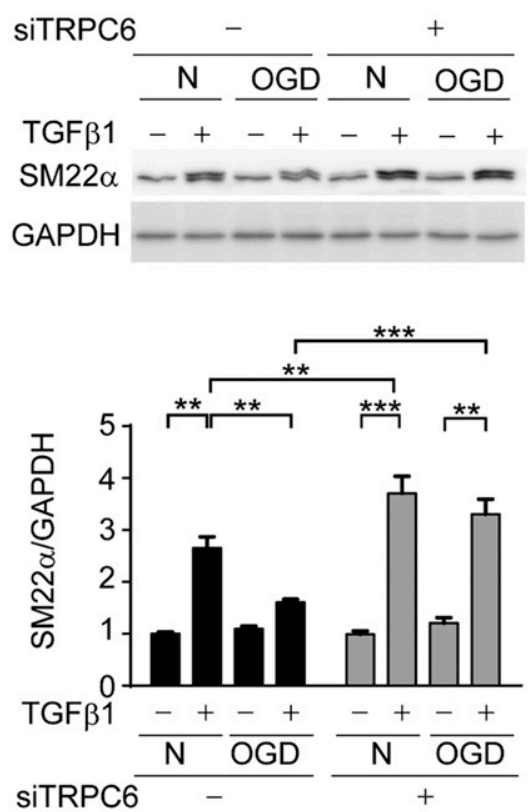

B
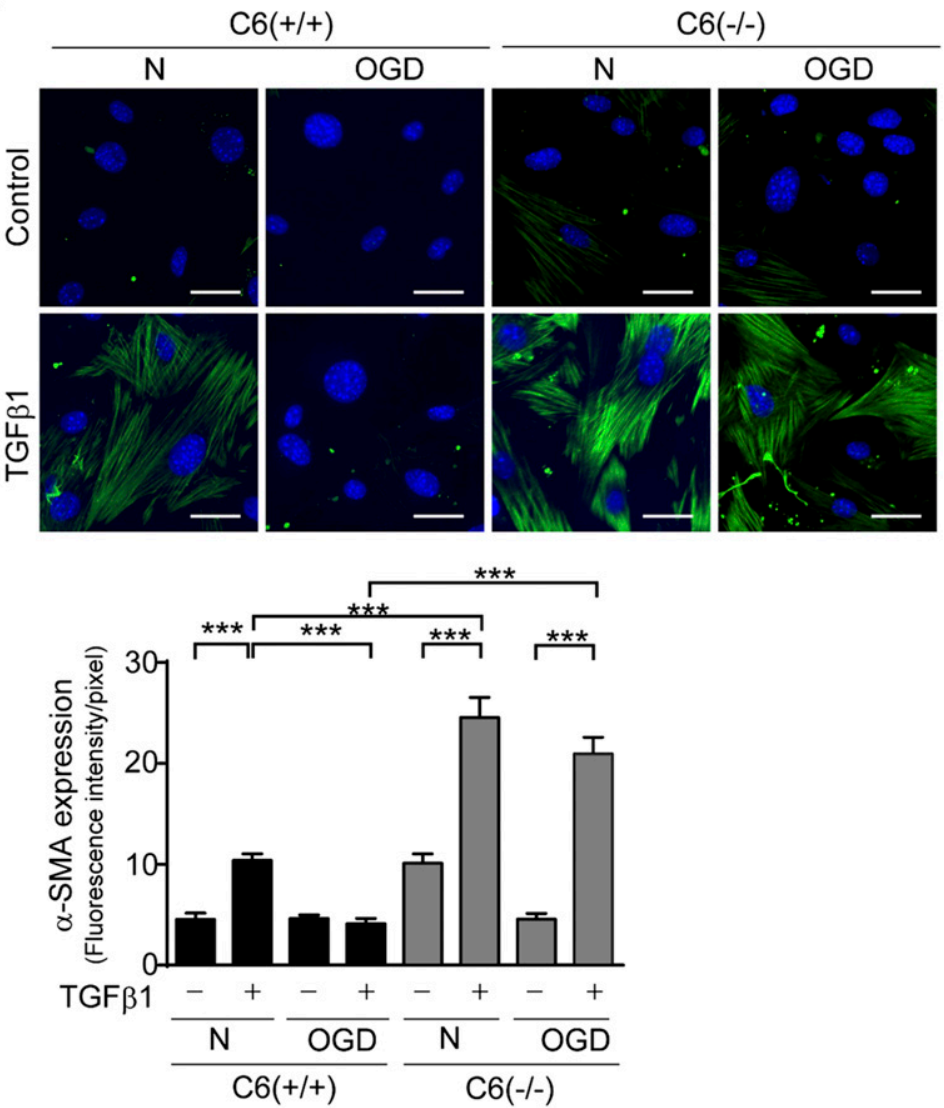

Figure 4. Ischemic conditions suppressed VSMC differentiation in a TRPC6-dependent manner. A) SM22 $\alpha$ expression in TGF- $\beta 1$ stimulated C3H10T1/2 cells after 24-h exposure to OGD or normoxic (N) conditions. Increases are shown relative to untreated siControl-transfected cells in $\mathrm{N}$ conditions $(n=5)$. Samples were loaded on the same gel. $B$ ) Representative images (upper) and quantitation (lower) of immunofluorescence of $\alpha$-SMA in VSMCs stimulated with TGF- $\beta 1(n=3)$. Scale bars, $20 \mu \mathrm{m}$. Cells were cultured in OGD condition for $24 \mathrm{~h}$ followed by stimulation with TGF- $\beta 1(5 \mathrm{ng} / \mathrm{ml})$ in normal culture medium and $\mathrm{O}_{2}$ level for 48 h. Nuclei were visualized with DAPI. GAPDH, glyceraldehyde 3-phosphate dehydrogenase. Data represent means \pm sEM. $* * P$ $<0.01, * * * P<0.001$.

increased $\alpha$-SMA immunofluorescence compared with TRPC6(+/+) cells in response to TGF- $\beta 1$ stimulation in normoxic conditions (Fig. 4B). Although OGD significantly inhibited TGF- $\beta 1$-induced VSMC differentiation of TRPC6(+/+) cells, TRPC6 deficiency abolished the suppression of VSMC differentiation elicited by OGD of primary VSMCs (Fig. 4B). These results suggest that down-regulation of TRPC6 during switching to the contractile phenotype is abrogated under pathologic conditions.

\section{TRPC6 interacts with PTEN and inhibits the Akt signaling pathway}

In our search for the downstream signaling machinery linking TRPC6 activity and Akt activation, we focused on the PTEN molecule. As PTEN is a lipid phosphatase, especially for $\mathrm{PI}(3,4,5) \mathrm{P}_{3}$, it is a common negative regulator of the PI3K/Akt signaling pathway. Previous reports suggest that TRPC6 interacts with PTEN in endothelial cells and VSMCs, and this interaction is important for cell surface expression of TRPC6 $(29,30)$. Based on these observations, we analyzed the interaction of TRPC6 and
PTEN during phenotypic switching under either physiologic or pathophysiological conditions. To analyze the interaction between endogenous proteins, we utilized a PLA. PLA results demonstrated that native TRPC6 interacted with PTEN in synthetic VSMCs but was significantly suppressed by TGF- $\beta 1$ treatment (Fig. 5A, B). OGD-treated proliferative VSMCs showed significantly increased TRPC6-PTEN interactions compared with cells in normoxic conditions (Fig. 5A, B). Moreover, a significant amount of TRPC6-PTEN interactions was retained in OGD-treated cells after TGF- $\beta 1$ stimulation (Fig. $5 A, B$ ). Consistent with these data, TRPC6(-/ -) VSMCs exhibited increased Akt activity compared with TRPC6(+/+) cells in response to TGF- $\beta 1$ stimulation (Fig. $5 C, D$ ). Furthermore, Akt activation was increased in OGD-treated TRPC6 $(-/-)$ cells upon TGF- $\beta 1$ stimulation comparable to normoxic cells (Fig. 5C,D). These data suggest that TRPC6 negatively regulated VSMC differentiation by suppressing Akt activity in close association with PTEN. Next, we analyzed the effect of OGD on resting membrane potential. OGD exposure prior to TGF- $\beta 1$ stimulation inhibited the negative shift of resting membrane potential in TRPC6 $(+/+)$ cells (Fig. 5E). In contrast, TGF- $\beta 1$-induced 


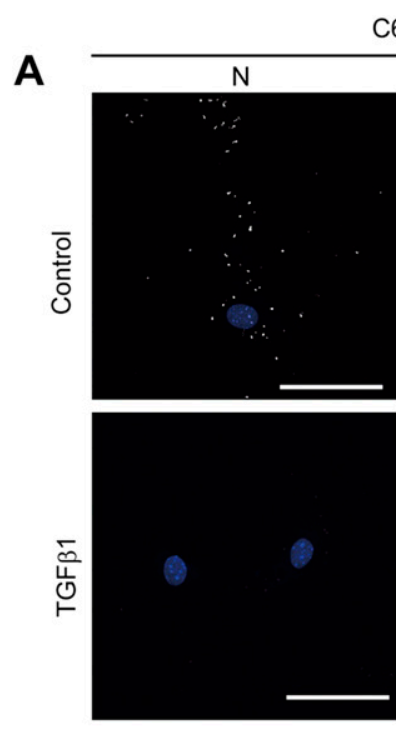

C

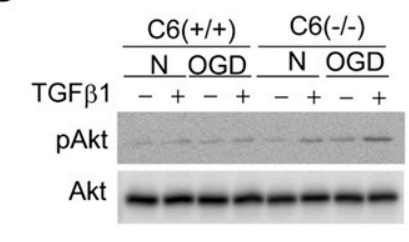

$6(+/+)$
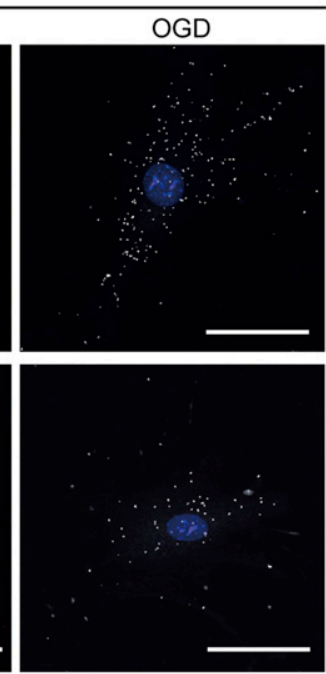

D

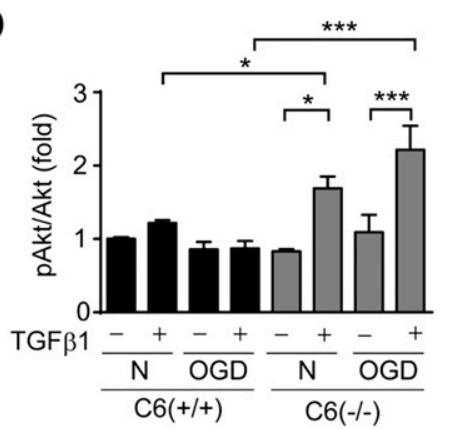

B

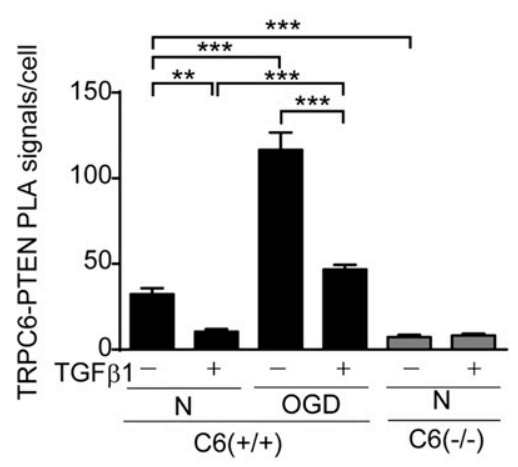

E

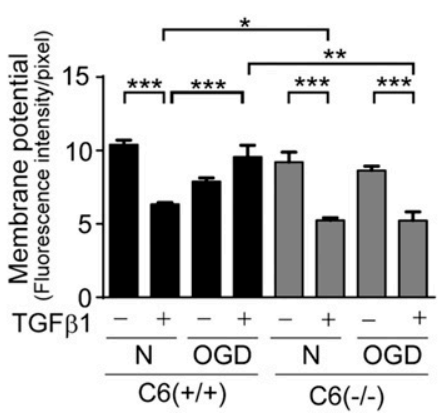

Figure 5. Ischemic conditions inhibited Akt activation via up-regulation of TRPC6-PTEN interaction and membrane depolarization in VSMCs. A) TRPC6-PTEN interaction in mouse VSMCs stimulated with TGF- $\beta 1$ following exposure to OGD or normoxic $(\mathrm{N})$ conditions as analyzed by Duolink PLA. Scale bars, $50 \mu \mathrm{m}$. Nuclei were visualized with DAPI. B) Quantitation of PLA signals in $A$ ( $n=18$ cells). C) TGF- $\beta 1$-induced Akt phosphorylation in mouse primary VSMCs isolated from C6 $(+/+)$ or C6 $(-/-)$ mice. Samples were loaded on the same gel. $D)$ Quantification of Akt phosphorylation $(n=3$ replicates); increases are shown relative to untreated $\mathrm{C} 6(+/+)$ cells in $\mathrm{N}_{\text {conditions. } E \text { ) Averaged DiBAC }}(3)$ fluorescence in VSMCs stimulated with TGF$\beta 1$ after exposure to OGD or $\mathrm{N}$ conditions ( $n=3$ replicates). Cells were cultured under OGD or $\mathrm{N}$ conditions for $24 \mathrm{~h}$ prior to TGF- $\beta 1$ stimulation $(5 \mathrm{ng} / \mathrm{ml}$ for $24 \mathrm{~h})$. pAkt, phosphorylated Akt. Data represent means \pm SEM. $* P<0.05, * * P<0.01$, $* * * P<$ 0.001 .

hyperpolarization of membrane potential in TRPC6 $(-/-)$ cells was insensitive to OGD preconditioning, indicating that the ischemic condition abrogated the polarization of resting membrane potential during VSMC differentiation by affecting TRPC 6 activity.

\section{Depolarization of membrane potential inhibited VSMC differentiation by maintaining PTEN membrane localization}

To analyze the importance of TRPC6-dependent changes of resting membrane potential in VSMC differentiation, C3H10T1/ 2 cells were treated with TGF- $\beta 1$ in the presence of additional extracellular $\mathrm{KCl}$. Supplementation of $\mathrm{KCl}$ suppressed VSMC differentiation in a dose-dependent manner (Fig. 6A), suggesting that membrane depolarization inhibited TGF- $\beta 1$-induced VSMC differentiation. PTEN possesses a C2 domain that is critical for its activation, as it brings PTEN to the plasma membrane. The C2 domain binds to anionic phospholipids such as phosphatidylserine (PS) and phosphatidylinositol in a $\mathrm{Ca}^{2+}$ dependent manner. Recent findings indicate that membrane potential affects the distribution of PS in the plasma membrane (31). Therefore, we analyzed the effect of membrane depolarization on localization of PTEN to the plasma membrane by supplementing cells with additional extracellular $\mathrm{KCl}$. The abundance of PTEN in the membrane fraction of C3H10T1/2 cells was significantly reduced by 48 -h TGF- $\beta 1$ stimulation (Fig. 6B). In contrast, there was no effect of excess $\mathrm{KCl}$ on the association of PTEN to the membrane in control cells. However, excess $\mathrm{KCl}$ suppressed the TGF- $\beta 1$-induced reduction of membrane-bound PTEN in differentiating cells (Fig. 6B), suggesting that membrane hyperpolarization in differentiating VSMCs is critical for inhibiting PTEN activation by keeping it away from the plasma membrane. To confirm the involvement of TRPC6 in PTEN membrane association, we analyzed relative quantities of membrane-bound PTEN in C3H10T1/2 cells transfected with siTRPC6. In this experiment, cells were treated with TGF- $\beta 1$ for $12 \mathrm{~h}$, during which PTEN was still well-associated in the membrane 
A

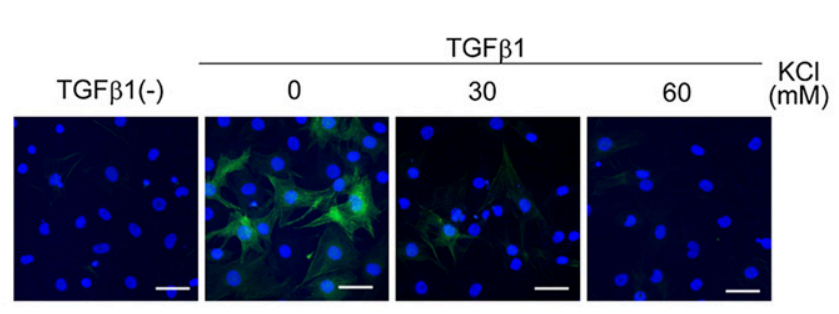

B
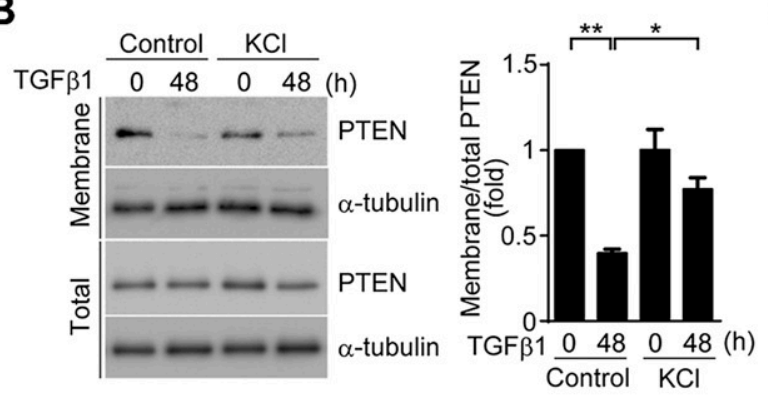

C

C
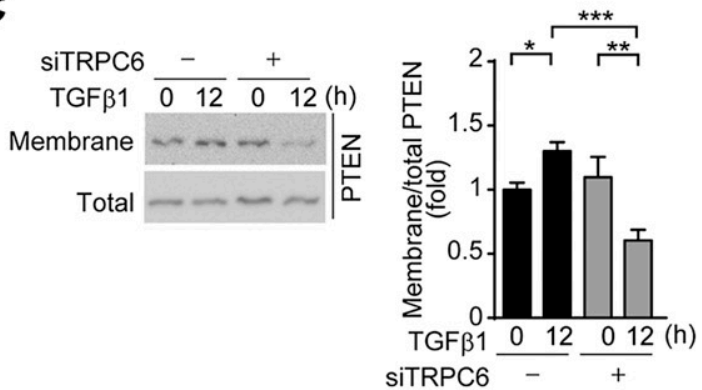

D

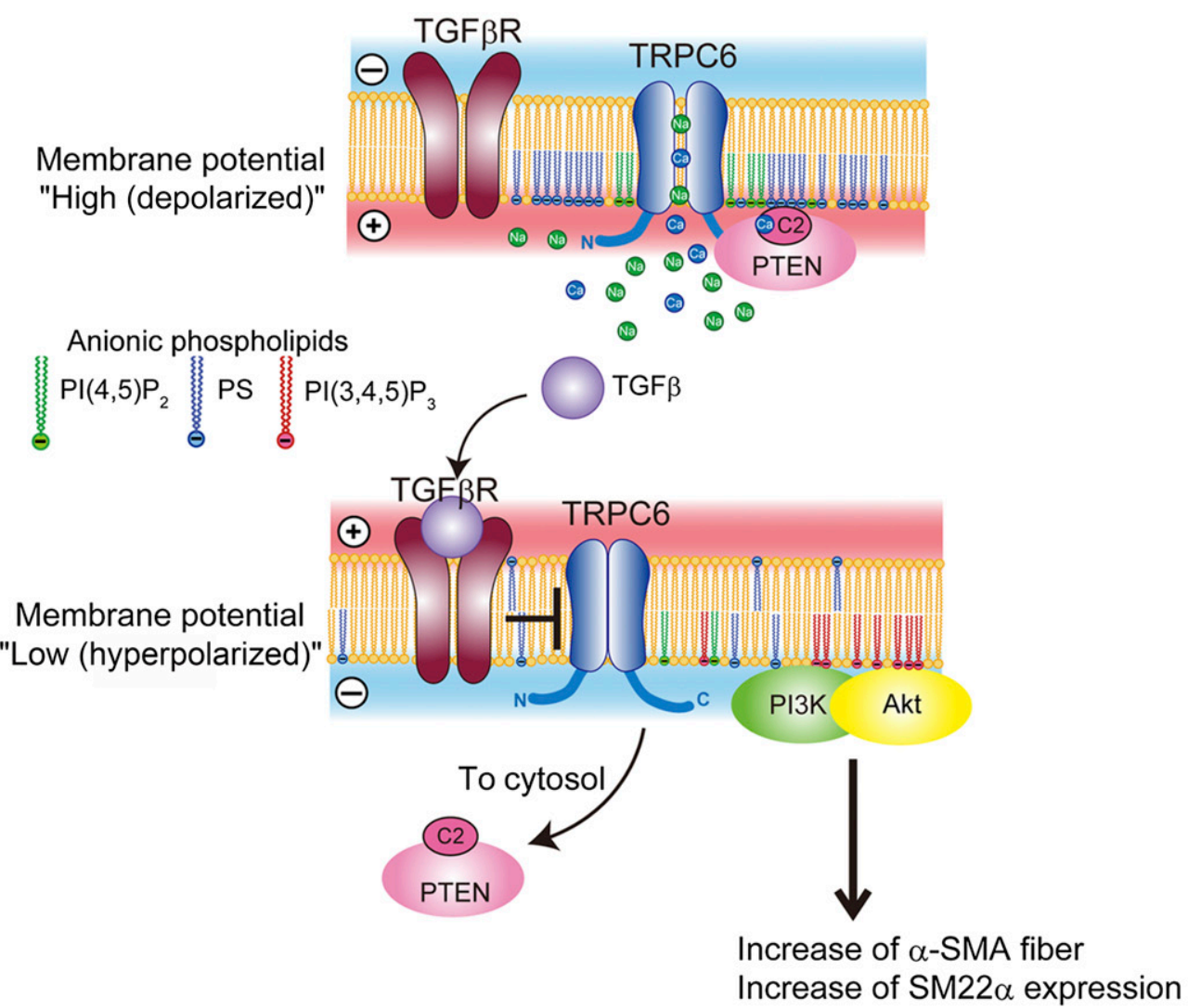

Figure 6. The mechanism by which TRPC6 contributes to VSMC differentiation. A) Immunofluorescence imaging of SM22 $\alpha$ in TGF- $\beta 1$ stimulated C3H10T1/2 cells in the presence of additional extracellular KCl. Cells were treated with TGF- $\beta 1$ and indicated concentrations of $\mathrm{KCl}$ for $48 \mathrm{~h}$. Representative images (left) and quantification of SM22 $\alpha$-positive cells (right) are shown $(n=5)$. Scale bars, $50 \mu \mathrm{m}$. Nuclei were visualized with DAPI. B) Membrane association of PTEN in TGF- $\beta 1$-stimulated C3H10T1/2 cells in the presence or absence of additional extracellular $\mathrm{KCl}(30 \mathrm{mM})$. Cells were treated with TGF- $\beta 1(5 \mathrm{ng} / \mathrm{ml})$ and $\mathrm{KCl}$ for $48 \mathrm{~h}$. Densitometric analysis of membraneassociated PTEN protein normalized to total PTEN protein (right, $n=5$ ); increases are shown relative to untreated control cells. $C$ ) PTEN membrane association in siRNA-transfected C3H10T1/2 cells. Cells were stimulated with TGF- $\beta 1$ ( $5 \mathrm{ng} / \mathrm{ml}$ ) for $12 \mathrm{~h}$. Increases are shown relative to untreated siControl-transfected cells. D) TRPC6 permeates $\mathrm{Na}^{+}$and $\mathrm{Ca}^{2+}$ in proliferating VSMCs, which causes a slight depolarization of membrane potential that affects anionic phospholipid distribution in the inner leaflet of the plasma membrane. The C2 domain of PTEN binds to $\mathrm{Ca}^{2+}$ in the proximal region of the mouth of the TRPC6 channel and brings PTEN close to the substrate PI(3,4,5) $\mathrm{P}_{3}$ in the plasma membrane via interaction with clustered anionic phospholipids such as PS. TGF- $\beta 1$ stimulation suppressed TRPC6 channel activity, which hyperpolarized membrane potential and inhibited $\mathrm{Ca}^{2+}$ influx, resulting in dissociation of PTEN from the plasma membrane and accumulation of $\mathrm{PI}(3,4,5) \mathrm{P}_{3}$ that induces Akt activation. ${ }^{*} P<0.05$, $* * P<0.01$, *** $P<0.001$. 
compartment in siControl-transfected cells (Fig. 6C). In contrast, TRPC6 knockdown significantly accelerated membrane dissociation of PTEN after 12-h TGF- $\beta 1$ stimulation (Fig. 6C). These data indicate that TRPC6 is important for both the membrane association of PTEN and membrane hyperpolarization, which involves the suppression of TRPC6 to trigger dissociation of PTEN from the membrane, thereby inducing VSMC differentiation marker expression (Fig. 6D).

\section{DISCUSSION}

In this study, we found that inhibition of TRPC6 channel activity facilitated VSMC differentiation via the hyperpolarization of membrane potential. Thus, TRPC6 functions to negatively regulate or maintain the synthetic phenotype of VSMCs. In synthetic VSMCs, PTEN can be activated at the plasma membrane through a functional and physical interaction with TRPC6, whereby PTEN reduces accumulation of $\mathrm{PI}(3,4,5) \mathrm{P}_{3}$. TGF- $\beta 1$ stimulation suppressed TRPC6 activation, which caused release of PTEN from the plasma membrane, $\mathrm{PI}(3,4,5) \mathrm{P}_{3}$ accumulation, and activation of Akt, a critical regulator of the switch to contractile phenotype of VSMCs (Fig. 6D).

TRPC 6 is a disease gene of IPAH. In patients with IPAH (32), TRPC6 expression is quite high compared with normal subjects (13). This up-regulation of TRPC6 is likely responsible for the increase of $\left[\mathrm{Ca}^{2+}\right]_{\mathrm{i}}$ observed in PASMCs (14). Indeed, increased $\left[\mathrm{Ca}^{2+}\right]_{\mathrm{i}}$ is the key determinant for transition from a contractile to synthetic phenotype of PASMCs $(14,33)$, and TRPC6 is believed to maintain the synthetic phenotype of PASMCs through regulation of $\mathrm{Ca}^{2+}$ influx. In this study, we also demonstrated that contractile VSMCs have less TRPC6 activity than synthetic cells. As a $\mathrm{Ca}^{2+}$ channel, this is consistent with data describing PASMCs. The importance of $\mathrm{Ca}^{2+}$ influx in VSMC phenotypic switching has been also demonstrated by research investigating other $\mathrm{Ca}^{2+}$-permeable channels, such as store-operated $\mathrm{Ca}^{2+}$ channels (SOCCs) composed of stromal interaction molecule 1 and Orai calcium release-activated calcium modulator 1 proteins (34-36). Several studies have reported increased SOCC components in pathologic conditions, which caused aberrant proliferation of SMCs in neointima formation or pulmonary hypertension $(14,33)$. These data suggest that SOCCs are more important for maintaining the synthetic phenotype rather than the contractile 1 . It has been recognized that VSMCs are heterogeneous among and within different tissues (37). Therefore, there is a concern about whether the importance of TRPC6 in phenotypic switching is specific for arterial smooth muscle cells. In this study, we utilized the mesenchymal stem cell line C3H10T1/2 and demonstrated that TGF- $\beta 1$-induced VSMC differentiation of those cells was also facilitated by TRPC6 suppression, suggesting that TRPC6-mediated maintenance of the synthetic phenotype is a universal mechanism of all VSMC lineages. Beyond the aspect of $\mathrm{Ca}^{2+}$ signaling, we were interested in the function of TRPC 6 as a nonselective cation channel, and demonstrated that it depolarizes membrane potential to activate voltage-gated $\mathrm{Ca}^{2+}$ channels, thus evoking the sustained $\mathrm{Ca}^{2+}$ influx required for activation of $\mathrm{Ca}^{2+}$-dependent transcription factors or vascular tonus regulation in cardiomyocytes or VSMCs, respectively (7, 23). Therefore, we investigated the effect of TRPC6 deficiency on membrane potential instead of $\mathrm{Ca}^{2+}$ signaling and showed that contractile VSMCs have a more polarized membrane potential than synthetic cells-a feature dependent on TRPC6. Contractile VSMCs are quiescent and minimally proliferative. As such, it is interesting that fully differentiated VSMCs have relatively polarized membrane potentials, whereas nondifferentiating stem cells exhibit depolarized membrane potentials (20). Therefore, TRPC6 might have universally important roles in the regulation of membrane potential in other cellular systems. However, current conducted by TRPC6 is not large. Thus, it is difficult to believe that TRPC6 directly regulates membrane potential through its channel activity. As such, how TRPC6 contributes to the regulation of membrane potential remains elusive and will be an important question for our future work.

PTEN acts as a major negative regulator of Akt by reducing $\mathrm{PI}(3,4,5) \mathrm{P}_{3}$. A few reports have demonstrated the interaction between TRPC6 and PTEN $(29,30)$; moreover, they demonstrated the importance of PTEN for surface expression of TRPC6. In this study, we demonstrated that TRPC6 could also regulate PTEN activity through a physical interaction. Indeed, this is a very reasonable coupling, as it has been revealed that TRPC6 channel activity requires phosphatidylinositol 4,5-bisphosphate for its full activation (38). Close association with PTEN can increase the local concentration of phosphatidylinositol 4,5-bisphosphate around TRPC6. Furthermore, $\mathrm{Ca}^{2+}$ influx mediated by TRPC6 can supply $\mathrm{Ca}^{2+}$ to the $\mathrm{C} 2$ domain of PTEN to maintain its membrane association. In this scenario, depolarization of membrane potential by TRPC6 is quite important. It has been reported that membrane depolarization induces cluster formation of anionic phospholipids such as PS and phosphatidylinositols (31). As membrane association of the C2 domain depends on the binding of $\mathrm{Ca}^{2+}$ and an anionic phospholipid (39), TRPC6-mediated $\mathrm{Ca}^{2+}$ influx may directly affect membrane recruitment of PTEN through its $\mathrm{C} 2$ domain (Fig. 6D). In addition, membrane depolarization also reportedly induces clustering of PS on the inner leaflet of the plasma membrane (31). Thus, TRPC6-mediated cation influx plays 2 roles for PTEN membrane recruitment: $\mathrm{Na}^{+} / \mathrm{Ca}^{2+}$ influx-mediated membrane depolarization induces clustering of PS and other anionic phospholipids, and $\mathrm{Ca}^{2+}$ influx-dependent binding of the $\mathrm{C} 2$ domain with an anionic phospholipid leads to recruitment of PTEN to the plasma membrane (Fig. 6D). In this study, we showed that membrane depolarization by the addition of excess $\mathrm{KCl}$ in the extracellular medium prevented TGF- $\beta 1$-induced PTEN dissociation from the membrane. This result supports the idea that resting membrane potential affects the distribution of anionic phospholipids in inner leaflet of the plasma membrane. This membrane potential-dependent regulation of phospholipid distribution would be important for C2 domain-dependent 
recruitment of PTEN to the plasma membrane. We previously demonstrated that TRPC 3 is a closely related isoform of TRPC 6 that couples with PKC $\beta$ to regulate its membrane translocation in a $\mathrm{C} 2$ domain-dependent manner (40). As the relationship between the distribution of anionic phospholipid and membrane potential is mostly unknown, this perspective might be an important clue for identifying the importance of membrane potential, especially in nonexcitable cells.

To analyze the possibility that TRPC6-mediated VSMC phenotype regulation plays a role in pathologic VSMCs, we utilized ischemic preconditioning by culturing cells in OGD condition before TGF- $\beta 1$ treatment as an in vitro disease model. OGD is one of the simplest ways to increase reactive oxygen species, the most critical disease driver, in native systems. OGD treatment abolished TGF- $\beta 1$ induced suppression of the TRPC6-PTEN interaction in VSMCs, thus forming a part of the underlying mechanism for inhibition of VSMC differentiation by OGD treatment. Therefore, synthetic VSMCs exposed to ischemic conditions lose the ability to differentiate into a VSMC-like phenotype in response to TGF- $\beta$, in part due to a lack of ability to inhibit TRPC6 channel activity and maintain the interaction between TRPC6 and PTEN. Therefore, loss of TRPC6 channel activity makes VSMCs more switchable to the contractile phenotype even under ischemic conditions. The search for a mechanism of inactivation of TRPC6 in contractile VSMCs and its inhibition by OGD is currently ongoing. However, the fact that suppression of TRPC6 can circumvent the effect of ischemia on VSMC differentiation implies TRPC6 is a novel drug target for atherosclerosis and diabetes in which proliferative VSMCs underlie poor prognostics (41).

\section{ACKNOWLEDGMENTS}

The authors thank Edanz Group (www.edanzediting.com/ac) for editing a draft of this manuscript. This research was funded by grants from JSPS KAKENHI [16H05092 and 19H03383 (to M.N.) and 17K15585 (to T.N.-T.)]; Scientific Research on Innovative Areas (Research in a Proposed Research Area 15K21759 "Oxygen Biology" to Y.M. and M.N., and 18H04993 "Living in Space" to T.N.-T.) from the Ministry of Education, Culture, Sports, Science, and Technology of Japan; Ono Medical Research Foundation (to M.N.); and by the Intramural Research Program of the U.S. National Institutes of Health (Bethesda, MD, USA) (Project ZO1-ES-101684 to L.B.). This work was also supported by the Cooperative Study Program of National Institute for Physiological Sciences and Spectrography and Bioimaging Facility, National Institute for Basic Biology Core Research Facilities. The authors declare no conflicts of interest.

\section{AUTHOR CONTRIBUTIONS}

M. Nishida supervised and conceived the project; T. Numaga-Tomita designed experiments and wrote the manuscript; T. Numaga-Tomita, T. Shimauchi, S. Oda, T. Tanaka, and K. Nishiyama performed experiments and interpreted data; A. Nishimura, L. Birnbaumer, and Y. Mori contributed reagents/analytic tools; and L. Birnbaumer and M. Nishida edited the manuscript.

\section{REFERENCES}

1. Owens, G. K., Kumar, M. S., and Wamhoff, B. R. (2004) Molecular regulation of vascular smooth muscle cell differentiation in development and disease. Physiol. Rev. 84, 767-801

2. Bennett, M. R., Sinha, S., and Owens, G. K. (2016) Vascular smooth muscle cells in atherosclerosis. Circ. Res. 118, 692-702

3. Davis-Dusenbery, B. N., Wu, C., and Hata, A. (2011) Micromanaging vascular smooth muscle cell differentiation and phenotypic modulation. Arterioscler. Thromb. Vasc. Biol. 31, 2370-2377

4. Frismantiene, A., Philippova, M., Erne, P., and Resink, T. J. (2018) Smooth muscle cell-driven vascular diseases and molecular mechanisms of VSMC plasticity. Cell. Signal. 52, 48-64

5. Hofmann, T., Obukhov, A. G., Schaefer, M., Harteneck, C., Gudermann, T., and Schultz, G. (1999) Direct activation of human TRPC6 and TRPC3 channels by diacylglycerol. Nature 397, 259-263

6. Inoue, R., Jensen, L. J., Shi, J., Morita, H., Nishida, M., Honda, A., and Ito, Y. (2006) Transient receptor potential channels in cardiovascular function and disease. Circ. Res. 99, 119-131

7. Nishioka, K., Nishida, M., Ariyoshi, M., Jian, Z., Saiki, S., Hirano, M., Nakaya, M., Sato, Y., Kita, S., Iwamoto, T., Hirano, K., Inoue, R., and Kurose, H. (2011) Cilostazol suppresses angiotensin II-induced vasoconstriction via protein kinase A-mediated phosphorylation of the transient receptor potential canonical 6 channel. Arterioscler. Thromb. Vasc. Biol. 31, 2278-2286

8. Otsuka, H., Akashi, H., Murohara, T., Okazaki, T., Shintani, S., Tayama, K., Sasaki, K., Imaizumi, T., and Aoyagi, S. (2006) The prostacyclin analog beraprost sodium augments the efficacy of therapeutic angiogenesis induced by autologous bone marrow cells. Ann. Vasc. Surg. 20, 646-652

9. Park, B., Hoffman, A., Yang, Y., Yan, J., Tie, G., Bagshahi, H., Nowicki, P. T., and Messina, L. M. (2010) Endothelial nitric oxide synthase affects both early and late collateral arterial adaptation and blood flow recovery after induction of hind limb ischemia in mice. J. Vasc. Surg. 51, 165-173

10. Waldron, G. J., and Cole, W. C. (1999) Activation of vascular smooth muscle $\mathrm{K}+$ channels by endothelium-derived relaxing factors. Clin. Exp. Pharmacol. Physiol. 26, 180-184

11. Takahashi, S., Lin, H., Geshi, N., Mori, Y., Kawarabayashi, Y., Takami, N., Mori, M. X., Honda, A., and Inoue, R. (2008) Nitric oxide-cGMP-protein kinase $\mathrm{G}$ pathway negatively regulates vascular transient receptor potential channel TRPC6. J. Physiol. 586, $4209-4223$

12. Yao, X. (2007) TRPC, cGMP-dependent protein kinases and cytosolic Ca2+. Handb. Exp. Pharmacol. 179, 527-540

13. Yu, Y., Fantozzi, I., Remillard, C. V., Landsberg, J. W., Kunichika, N., Platoshyn, O., Tigno, D. D., Thistlethwaite, P. A., Rubin, L. J., and Yuan, J. X. (2004) Enhanced expression of transient receptor potential channels in idiopathic pulmonary arterial hypertension. Proc. Natl. Acad. Sci. USA 101, 13861-13866

14. Fernandez, R. A., Wan, J., Song, S., Smith, K. A., Gu, Y., Tauseef, M., Tang, H., Makino, A., Mehta, D., and Yuan, J. X. (2015) Upregulated expression of STIM2, TRPC6, and Orai2 contributes to the transition of pulmonary arterial smooth muscle cells from a contractile to proliferative phenotype. Am. J. Physiol. Cell Physiol. 308, C581-C593

15. Nishimura, A., Sunggip, C., Tozaki-Saitoh, H., Shimauchi, T., Numaga-Tomita, T., Hirano, K., Ide, T., Boeynaems, J. M., Kurose, H., Tsuda, M., Robaye, B., Inoue, K., and Nishida, M. (2016) Purinergic P2Y6 receptors heterodimerize with angiotensin AT1 receptors to promote angiotensin II-induced hypertension. Sci. Signal. $\mathbf{9}$, ra7

16. Kiyonaka, S., Kato, K., Nishida, M., Mio, K., Numaga, T., Sawaguchi,Y., Yoshida, T., Wakamori, M., Mori, E., Numata, T., Ishii, M., Takemoto, H., Ojida, A., Watanabe, K., Uemura, A., Kurose, H., Morii, T., Kobayashi, T., Sato, Y., Sato, C., Hamachi, I., and Mori, Y. (2009) Selective and direct inhibition of TRPC3 channels underlies biological activities of a pyrazole compound. Proc. Natl. Acad. Sci. USA 106, 5400-5405

17. Schaper, W. (2009) Collateral circulation: past and present. Basic Res. Cardiol. 104, 5-21

18. Leuner, K., Kazanski, V., Müller, M., Essin, K., Henke, B., Gollasch, M., Harteneck, C., and Müller, W.E. (2007) Hyperforin-a key constituent of St. John's wort specifically activates TRPC6 channels. FASEB J. 21, 4101-4111

19. Tu, P., Gibon, J., and Bouron, A. (2010) The TRPC6 channel activator hyperforin induces the release of zinc and calcium from mitochondria. J. Neurochem. 112, 204-213 
20. Levin, M. (2012) Molecular bioelectricity in developmental biology: new tools and recent discoveries: control of cell behavior and pattern formation by transmembrane potential gradients. BioEssays 34, 205-217

21. Inoue, R., Okada, T., Onoue, H., Hara, Y., Shimizu, S., Naitoh, S., Ito, Y., and Mori, Y. (2001) The transient receptor potential protein homologue TRP6 is the essential component of vascular alpha(1)-adrenoceptor-activated $\mathrm{Ca}(2+)$-permeable cation channel. Circ. Res. 88, 325-332

22. Ichikawa, J., and Inoue, R. (2014) TRPC6 regulates cell cycle progression by modulating membrane potential in bone marrow stromal cells. Br. J. Pharmacol. 171, 5280-5294

23. Onohara, N., Nishida, M., Inoue, R., Kobayashi, H., Sumimoto, H., Sato, Y., Mori, Y., Nagao, T., and Kurose, H. (2006) TRPC3 and TRPC6 are essential for angiotensin II-induced cardiac hypertrophy. EMBO J. 25, 5305-5316

24. Hirschi, K. K., Rohovsky, S. A., and D'Amore, P. A. (1998) PDGF, TGF-beta, and heterotypic cell-cell interactions mediate endothelial cell-induced recruitment of $10 \mathrm{~T} 1 / 2$ cells and their differentiation toa smooth muscle fate. J. Cell Biol. 141, 805-814; erratum: 1287

25. Johansson-Percival, A., Li, Z. J., Lakhiani, D. D., He, B., Wang, X., Hamzah, J., and Ganss, R. (2015) Intratumoral LIGHT restores pericyte contractile properties and vessel integrity. Cell Reports 13, 2687-2698

26. Shi, N., Xie, W. B., and Chen, S. Y. (2012) Cell division cycle 7 is a novel regulator of transforming growth factor- $\beta$-induced smooth muscle cell differentiation. J. Biol. Chem. 287, 6860-6867

27. Lien, S. C., Usami, S., Chien, S., and Chiu, J. J. (2006) Phosphatidylinositol 3-kinase/Akt pathway is involved in transforming growth factor-betal-induced phenotypic modulation of 10T1/2 cells to smooth muscle cells. Cell. Signal. 18, 1270-1278

28. Burtenshaw, D., Hakimjavadi, R., Redmond, E. M., and Cahill, P. A. (2017) Nox, reactive oxygen species and regulation of vascular cell fate. Antioxidants 6, E90

29. Kini, V., Chavez, A., and Mehta, D. (2010) A new role for PTEN in regulating transient receptor potential canonical channel 6-mediated Ca2+ entry, endothelial permeability, and angiogenesis. J. Biol. Chem. 285, 33082-33091

30. Monet, M., Francoeur, N., and Boulay, G. (2012) Involvement of phosphoinositide 3-kinase and PTEN protein in mechanism of activation of TRPC6 protein in vascular smooth muscle cells. J. Biol. Chem. 287, 17672-17681

31. Zhou, Y., Wong, C. O., Cho, K. J., van der Hoeven, D., Liang, H., Thakur, D. P., Luo, J., Babic, M., Zinsmaier, K. E., Zhu, M. X., Hu, H., Venkatachalam, K., and Hancock, J. F. (2015) Membrane potential modulates plasma membrane phospholipid dynamics and K-Ras signaling. Science 349, 873-876

32. Malczyk, M., Erb, A., Veith, C., Ghofrani, H. A., Schermuly, R. T., Gudermann, T., Dietrich, A., Weissmann, N., and Sydykov, A. (2017) The role of transient receptor potential channel 6 channels in the pulmonary vasculature. Front. Immunol. 8, 707

33. Golovina, V. A., Platoshyn, O., Bailey, C. L., Wang, J., Limsuwan, A., Sweeney, M., Rubin, L. J., and Yuan, J. X. (2001) Upregulated TRP and enhanced capacitative $\mathrm{Ca}(2+)$ entry in human pulmonary artery myocytes during proliferation. Am. J. Physiol. Heart Circ. Physiol. 280, H746-H755

34. Mancarella, S., Potireddy, S., Wang, Y., Gao, H., Gandhirajan, R. K., Autieri, M., Scalia, R., Cheng, Z., Wang, H., Madesh, M., Houser, S. R., and Gill, D. L. (2013) Targeted STIM deletion impairs calcium homeostasis, NFAT activation, and growth of smooth muscle. FASEBJ 27, 893-906

35. Merlet, E., Atassi, F., Motiani, R. K., Mougenot, N., Jacquet, A., Nadaud, S., Capiod, T., Trebak, M., Lompré, A. M., and Marchand, A. (2013) miR-424/322 regulates vascular smooth muscle cell phenotype and neointimal formation in the rat. Cardiovasc. Res. $\mathbf{9 8}$, $458-468$

36. Berra-Romani, R., Mazzocco-Spezzia, A., Pulina, M. V., and Golovina V.A. (2008) Ca2+ handling is altered when arterial myocytes progress from a contractile to a proliferative phenotype in culture. Am. J. Physiol. Cell Physiol. 295, C779-C790

37. Muto, A., Fitzgerald, T. N., Pimiento, J. M., Maloney, S. P., Teso, D. Paszkowiak, J. J., Westvik, T. S., Kudo, F. A., Nishibe, T., and Dardik, A. (2007) Smooth muscle cell signal transduction: implications of vascular biology for vascular surgeons. J. Vasc. Surg. 45, A15-A24

38. Itsuki, K., Imai, Y., Hase, H., Okamura, Y., Inoue, R., and Mori, M. X. (2014) PLC-mediated PI(4,5)P2 hydrolysis regulates activation and inactivation of TRPC6/7 channels. J. Gen. Physiol. 143, 183-201

39. Corbalan-Garcia, S., and Gómez-Fernández, J. C. (2014) Signaling through C2 domains: more than one lipid target. Biochim. Biophys. Acta 1838, 1536-1547

40. Numaga, T., Nishida, M., Kiyonaka, S., Kato, K., Katano, M., Mori, E., Kurosaki, T., Inoue, R., Hikida, M., Putney, J. W., Jr., and Mori, Y. (2010) Ca2+ influx and protein scaffolding via TRPC3 sustain PKCbeta and ERK activation in B cells. J. Cell Sci. 123, 927-938

41. Chiong, M., Morales, P., Torres, G., Gutiérrez, T., García, L., Ibacache, M., and Michea, L. (2013) Influence of glucose metabolism on vascular smooth muscle cell proliferation. Vasa 42 , 8-16

Received for publication December 24, 2018 Accepted for publication April 29, 2019 